\title{
Management of raised blood pressure in New Zealand: a discussion document
}

\author{
R Jackson, P Barham, J Bills, T Birch, L McLennan, S MacMahon, T Maling
}

Department of Community Health, University of Auckland, Auckland, New Zealand

$\mathrm{R}$ Jackson, senior lecturer in epidemiology

Goodfellow Unit, Department of General Practice, University of Auckland

P Barham, director

\section{Rotherham Medical}

Centre, Rotheram, North

Canterbury, New Zealand

J Bills, general practitioner

Hokianga Health Services, Rawene, New Zealand

T Birch, general practitioner

Waitangirua Health

Centre, Porirua,

Wellington, New Zealand

L McLennan, general

practitioner

Clinical Trials Research

Unit, Department of

Medicine, University of

Auckland

S MacMahon, director

Department of Medicine, Wellington School of Medicine, University of Otago, New Zealand

T Maling, associate professor of medicine

Correspondence to: Dr R Jackson, Department of Community Health,

School of Medicine,

University of Auckland,

Private Bag 92019,

Auckland, New Zealand.

BMF 1993;307:107-10

Relative and absolute effects (\%) of reducing diastolic blood pressure by $5-6 \mathrm{~mm} \mathrm{Hg}$

A report to the National Advisory Committee on Core Health and Disability Support Services, New Zealand, on the management of raised blood pressure recommends that decisions to treat raised blood pressure should be based primarily on the estimated absolute risk of cardiovascular disease rather than on blood pressure alone. In general, patients with a blood pressure of 150-170 mm $\mathrm{Hg}$ systolic or $90-100$ $\mathrm{mm} \mathrm{Hg}$ diastolic, or both, should be given treatment to lower blood pressure if the risk of a major cardiovascular disease event in 10 years is more than about $20 \%$. The results of clinical trials indicate that, at this level of absolute risk, 150 people would require treatment to reduce the annual number of cardiovascular events by about one.

Implementation of these recommendations may result in a smaller proportion of people aged under 60 , particularly women, receiving treatment but an increased proportion of older people treated. In the absence of specific contraindications, low dose diuretics and low dose $\beta$ blockers should be considered for first line treatment, since for only these drug groups is there direct evidence of reduced risk of stroke and coronary disease in people with raised blood pressure.

The treatment of raised blood pressure has changed substantially in the past 40 years. ${ }^{1}$ In the 1950 s the first drugs for lowering blood pressure were used primarily to treat individuals with malignant or accelerated hypertension. This was often a symptomatic disorder characterised by very high blood pressure, which was usually fatal if left untreated. Since the 1960 s numerous clinical trials have shown that treating less extreme cases of raised blood pressure reduces patients' risks of developing cardiovascular disease-mainly stroke, coronary heart disease, and renal disease. These trials have led to a progressive lowering of the blood pressure at which doctors start antihypertensive treatment.

Most people who are now treated for raised blood pressure do not have symptomatic disease. Their raised blood pressure, however, increases their risk of developing cardiovascular disease in the future relative to similar individuals with lower blood pressure. Thus high blood pressure is a risk factor for disease but not a disease in itself. Only a small proportion of people with

\begin{tabular}{lcc}
\hline & $\begin{array}{c}60 \text { Year old woman with initial } \\
\text { diastolic blood pressure of } 100 \\
\text { mm Hg and no other risk factors for } \\
\text { cardiovascular disease }\end{array}$ & $\begin{array}{c}\text { 70 Year old man with initial } \\
\text { diastolic blood pressure of } 95 \\
\text { mm Hg and multiple risk factors } \\
\text { for cardiovascular disease }\end{array}$ \\
\hline $\begin{array}{l}\text { Absolute risk of cardiovascular } \\
\text { event in } 10 \text { years }(\%):\end{array}$ & & \\
$\begin{array}{l}\text { Before treatment } \\
\text { After treatment }\end{array}$ & 10 & 50 \\
Absolute reduction of risk & 7 & 33 \\
$\begin{array}{l}\text { Relative reduction of } \\
\text { risk }\end{array}$ & $3(10-7)$ & $17(50-33)$ \\
\hline
\end{tabular}

raised blood pressure have serious underlying medical disorders. Studies of outcome associated with different blood pressures indicate that the relative risk of cardiovascular disease increases steadily with increasing blood pressure. ${ }^{2}$ There is, however, no specific point at which blood pressure becomes dangerously high so the definition of high blood pressure is somewhat arbitrary. This raises the question of when the risk of cardiovascular disease for a patient with raised blood pressure is high enough to warrant treatment.

Some people with raised blood pressure but no other major risk factor for cardiovascular disease may have a low absolute risk of developing the disease. For example, of 100 women aged 60 with mildly raised blood pressure but no other important risk factor for cardiovascular disease, 10 at most are likely to have a major cardiovascular event (stroke, myocardial infarction, or coronary death) in the next 10 years. ${ }^{3}$ Thus $90 \%$ of the women would remain free of disease for the 10 years. Most current clinical guidelines for the management of raised blood pressure, however, are based largely on blood pressure while other risk factors affecting absolute risk, although they are considered, are given less emphasis. ${ }^{4-6}$ This means that a 60 year old woman with a diastolic blood pressure of $100 \mathrm{~mm} \mathrm{Hg}$ but no other risk factor-an absolute risk of cardiovascular disease of about $10 \%$ in 10 years ${ }^{3}$-may meet the criteria for treatment whereas a 70 year old man with multiple risk factors but a diastolic blood pressure of $95 \mathrm{~mm} \mathrm{Hg}$ - an absolute risk of about $50 \%$ in 10 years-may not.

\section{Costs and benefits of treatment}

Clinical trials suggest that whatever the initial absolute risk of cardiovascular disease, reducing blood pressure will reduce the relative risk of disease by about the same proportion. ${ }^{7}$ Reviews of randomised trials indicate that lowering diastolic blood pressure by about 5-6 $\mathrm{mm} \mathrm{Hg}$ (and systolic blood pressure by about $10 \mathrm{~mm} \mathrm{Hg}$ ) reduces the relative risk of stroke by about $35-40 \%$ and of coronary heart disease by $15-20 \%$. Therefore, if lowering blood pressure by this amount would reduce the overall risk of a cardiovascular event by about one third in both the 60 year old woman and 70 year old man described above, then treating the woman would reduce her absolute risk in 10 years by about 3\% whereas treating the man would reduce his absolute risk by about $17 \%$ (see table).

Treating people with raised blood pressure but a low absolute risk of cardiovascular disease raises the question of whether such people gain sufficient benefits to outweigh the possible side effects of treatment. Given the need to manage limited resources efficiently, the cost effectiveness of treatment is also an important consideration. If, say, 100 women require treatment for 10 years to prevent three cardiovascular events the cost of preventing each event will be much higher 
than that of treating 100 men at high risk and preventing about 17 events. The cost effectiveness of treatment will depend not only on the absolute risk but also on the choice of medication because of the different costs and side effects of various drugs. Unfortunately only limited information about cost effectiveness is available for methods of lowering blood pressure, and it is therefore premature to base guidelines for treatment primarily on cost effectiveness.

In the past 20 years the introduction of better tolerated but more expensive drugs and the progressive lowering of the blood pressure at which treatment is recommended have meant that the number of people treated and the costs of treatment have increased substantially. In New Zealand the current annual cost of drugs for lowering blood pressure is about $\$ N Z 80$ 100 million (about $15 \%$ of the total national drug bill). Between $15 \%$ and $20 \%$ of middle aged New Zealanders and more than a quarter of those aged over 65 regularly take drugs for lowering blood pressure. ${ }^{8}$

\section{Recommendations}

In this report we attempt to quantify the level of absolute risk of cardiovascular disease at which treatment should be considered more explicitly than has been done in previous guidelines. The recommendations are based on the premise that, in most cases, raised blood pressure is a risk factor for cardiovascular disease rather than a disease in its own right. They do not cover in detail the management of accelerated hypertension or secondary hypertension. Some of the issues raised, particularly those relating to the absolute risk at which treatment should be contemplated and how much individuals or the public health services should pay to prevent a disease event, require public debate.

OBJECTIVES OF TREATING RAISED BLOOD PRESSURE

- The main objective of reducing blood pressure in a person with raised blood pressure is to reduce the absolute risk of premature death and disease, primarily by decreasing the risk of coronary heart disease and stroke.

- Treatment to lower blood pressure is indicated when the treatment's benefits are thought to outweigh its adverse effects and when its cost effectiveness is similar to that of other accepted interventions.

\section{INDIVIDUALS REQUIRING EVALUATION}

- Randomised trials have shown that antihypertensive drug treatment benefits people whose diastolic blood pressure (phase V) is consistently greater than $90 \mathrm{~mm}$ $\mathrm{Hg}$ or whose systolic blood pressure is above $150 \mathrm{~mm}$ $\mathrm{Hg}$. At blood pressures higher than these, other risk factors for cardiovascular disease should be evaluated to determine whether the absolute risk to an individual is high enough to justify pharmacological treatment.

\section{ESTIMATION OF RISK}

- In general the absolute risk of cardiovascular disease is determined more by other risk factors than by raised blood pressure. Sufficient information should be collected about major risk factors to allow estimation of the absolute risk of cardiovascular disease before a decision is made about treating blood pressure.

- Important risk factors for cardiovascular disease include increasing age; cigarette smoking; a high concentration of total cholesterol or a low concentration of high density lipoprotein, or both; diabetes; male sex; and a family history of premature coronary heart disease. People with familial hyperlipidaemia, previous cardiovascular disease, or other end organ damage, such as renal disease, are at particularly high risk.

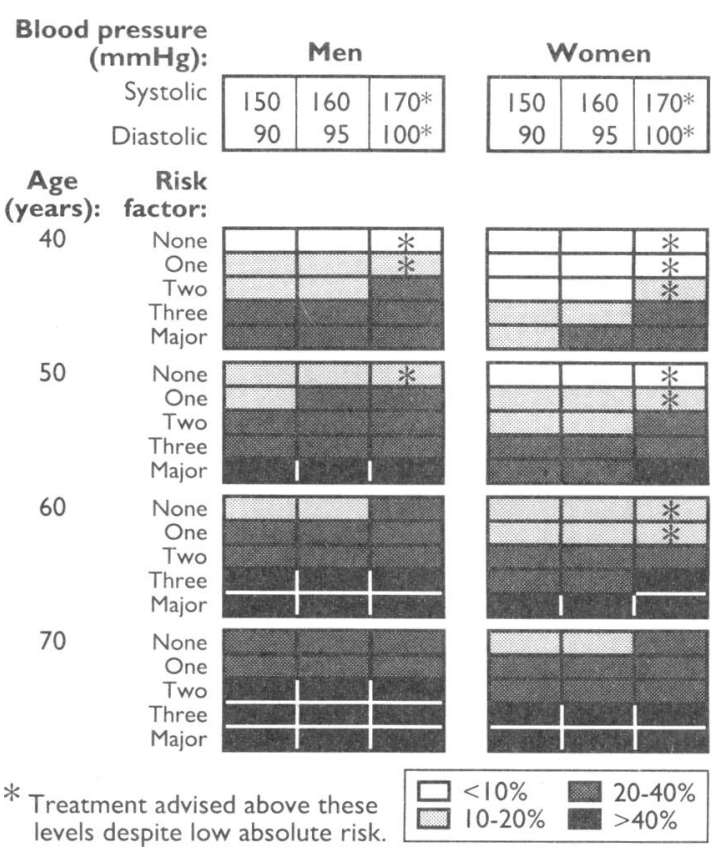

Absolute risk (\%) of having a cardiovascular event in 10 years according to age, blood pressure, and other risk factors

- The figure shows how the absolute risk of cardiovascular disease is affected by combinations of risk factors. This is mainly based on data from the Framingham study, but the information has been rounded for simplicity and additional risk factors are considered as present or absent. Thus the figure is an approximate guide only. More accurate risk calculators are available that incorporate different levels of each risk factor in to the risk equation. The risk factors other than blood pressure were cigarette smoking, diabetes, a ratio of cholesterol to high density lipoprotein of $>6: 1$, a body mass index (weight $(\mathrm{kg}) /$ (height $(\mathrm{m}))^{2}$ ) of $>30$, and a family history of premature cardiovascular disease (in a parent or sibling before the age of 55). A major risk factor included symptomatic cardiovascular disease or a factor highly predictive of cardiovascular disease: myocardial infarction, stroke, transient ischaemic attacks, peripheral vascular disease, coronary angioplasty or bypass surgery, silent ischaemia, left ventricular hypertrophy, and familial hyperlipidaemia.

\section{MEASUREMENT OF BLOOD PRESSURF}

- The blood pressure of all adults aged over 30 should be measured at least once every five years during visits to their general practitioners. Blood pressure should preferably be measured in the context of total health care to allow assessment of all relevant risk factors for cardiovascular disease. In patients at increased absolute risk of cardiovascular disease (more than about $15-20 \%$ in 10 years) blood pressure should be measured about every two years.

- General population screening to identify people with raised blood pressure is not recommended because it is a very inefficient method of identifying those requiring treatment.

- Multiple measurements should be made on several occasions before treatment is considered.

- Systolic and diastolic (phase V Korotkoff sound) blood pressure should be measured. Systolic blood pressure is at least as important as diastolic blood pressure in determining risk and tends to be a better predictor of the risk of cardiovascular disease.

- Secondary causes of raised blood pressure should be excluded. 
WHO SHOULD BE TREATED?

- Depending on the initial absolute risk, the benefits of lowering blood pressure range from preventing one cardiovascular event a year for about every 20 people treated to preventing one event for about every 500010000 people treated. The level of risk at which treatment should be started is debatable.

- We recommend that people with an estimated absolute risk of cardiovascular disease of about $20 \%$ or more in 10 years and a sustained blood pressure greater than $150 \mathrm{~mm} \mathrm{Hg}$ systolic or $90 \mathrm{~mm} \mathrm{Hg}$ diastolic (phase V) should be considered for treatment to lower blood pressure (see figure to estimate risk). Lowering the blood pressure of these patients by an average of 5-6 $\mathrm{mm} \mathrm{Hg}$ diastolic (and $10 \mathrm{~mm} \mathrm{Hg}$ systolic) would reduce their risk of cardiovascular disease by about one third. In those with an absolute risk of $20 \%$ in 10 years the risk would be reduced to about $13 \%$ in 10 years, meaning that one event would be prevented for every 150 patients treated a year. Any adverse effects of treatment are unlikely to outweigh the benefits of treatment at this level of risk and treatment is likely to be relatively cost effective. The absolute benefits and cost effectiveness of treatment would be greater if larger reductions of blood pressure could be achieved.

- Younger people, particularly those in their 20s and 30 s, with a sustained average blood pressure greater than $150 \mathrm{~mm} \mathrm{Hg}$ systolic or $90 \mathrm{~mm} \mathrm{Hg}$ diastolic (phase V) should generally be referred to a specialist whatever the estimated absolute risk: high blood pressure in younger people is an important risk factor for accelerated hypertension, and there is a greater probability of secondary causes of raised blood pressure.

- People aged 40-60 with sustained blood pressure levels above $170 \mathrm{~mm} \mathrm{Hg}$ systolic or $100 \mathrm{~mm} \mathrm{Hg}$ diastolic but with an absolute risk of cardiovascular disease below $20 \%$ in 10 years may be considered for treatment because the higher the blood pressures, the greater the rate of increase over time and the greater the risk of accelerated hypertension. Moreover, given current practice it would be difficult to convince doctors not to treat such people despite their low absolute risk. If treatment is not started blood pressure should be monitored frequently. People over 60 with similar blood pressures are at high absolute risk and should be considered for treatment as described above.

- Increasing age is not a contraindication to treatment and is often an important indication. Older people generally have a higher absolute risk of cardiovascular disease and therefore derive greater benefit from treatment. Most of the evidence from randomised trials, however, has been obtained from people aged under 80 , and there remains some uncertainty about the size of the benefit above this age.

- Patients should be informed of their approximate absolute risk of cardiovascular disease and counselled about ways to reduce the risk. They should be given a choice between pharmacological and behavioural treatments.

\section{CHOICE OF TREATMENTS}

- The most effective behavioural methods for lowering blood pressure are reducing weight, restricting salt intake, taking regular moderate exercise, and restricting alcohol consumption (no more than three standard drinks a day). Other important behavioural means of reducing risk of cardiovascular disease are stopping smoking and reducing dietary saturated fats.

- If behavioural treatment is unsuccessful in reducing the absolute risk of cardiovascular disease to an acceptable level (below about $20 \%$ in 10 years) drug treatment should be considered after about six months. If a patient's absolute risk is very high or blood pressure exceeds $180 / 105 \mathrm{~mm} \mathrm{Hg}$ drug treatment should be considered earlier.

- Low dose diuretics and low dose $\beta$ blockers should be considered as first line treatment unless there are contraindications or specific indications for using other drugs. These are the only classes of drug which have been shown in randomised clinical trials to reduce the risk of cardiovascular events among patients treated for raised blood pressure. More recently developed drug classes (such as angiotensin converting enzyme inhibitors, calcium antagonists, and $\alpha$ blockers) may have some advantages for preventing cardiovascular disease, but, until randomised trials have shown that they are as or more effective than diuretics or $\beta$ blockers, they should probably be considered as second line treatment.

- Initial drug treatment should generally be a low dose diuretic such as $1 \cdot 25-2 \cdot 5 \mathrm{mg}$ bendrofluazide daily or $12.5 \mathrm{mg}$ hydrochlorothiazide daily. A dose of $1.25 \mathrm{mg}$ bendrofluazide daily has minimal effect on lipid, glucose, and potassium metabolism yet is as effective in lowering blood pressure as a dose of $5-10 \mathrm{mg}$. $^{9}$

- If there are contraindications to using a diuretic (for example, gout, hypokalaemia, or diabetes) or specific indications for using a $\beta$ blocker (for example, concurrent angina or recent myocardial infarction) a low dose $\beta$ blocker should be considered as first line treatment (such as $50 \mathrm{mg}$ atenolol daily, $100 \mathrm{mg}$ metoprolol daily, or the equivalent dose of another $\beta$ blocker).

\section{REVIEWING TREATMENTS}

- Initial review and adjustment of medication is not usually required for about one month unless blood pressure level is considered to be acutely dangerous. Low dose diuretics and $\beta$ blockers can take up to two months to produce their maximum effect.

- If there is an inadequate response to $1 \cdot 25-2.5 \mathrm{mg}$ bendrofluazide daily (or its equivalent) after three months, or if there are adverse effects, it is generally better to change to a low dose $\beta$ blocker than to increase the dose of diuretic. Increasing the dose of bendrofluazide above $2.5 \mathrm{mg}$ daily does not usually lower the blood pressure any further. ${ }^{9}$

- If there are significant side effects, poor compliance, contraindications, or an inadequate response to a low dose $\beta$ blocker after three months a second line drug should be considered.

- The purpose of lowering blood pressure is to reduce the absolute risk of cardiovascular disease. Observational studies suggest that larger reductions of blood

Clinical implications
- The decision to treat raised blood pressure is
currently based primarily on the blood pressure
The risk of disease associated with raised
blood pressure depends mainly on the presence
or absence of other risk factors
This report recommends that clinicians base
their decision to treat raised blood pressure
primarily on the estimated risk of developing
cardiovascular disease rather than on blood
pressure
- Patients with blood pressures of $150-170$
mm Hg systolic or $90-100$ mm Hg diastolic
should be considered for treatment if their risk
of cardiovascular disease in 10 years is about
$20 \%$ or more


pressure should produce greater benefits, but this has not been studied in randomised trials. It has been suggested that lowering diastolic blood pressure below $90 \mathrm{~mm} \mathrm{Hg}$ in patients with coronary heart disease may have adverse effects. ${ }^{10}$ Randomised trials of $\beta$ blockers and angiotensin converting enzyme inhibitors in patients with coronary heart disease do not support the existence of such adverse effects. ${ }^{11} 12$

- Once their blood pressure is stabilised most patients require only six monthly follow up.

The report was commissioned by the National Advisory Committee on Core Health and Disability Support Services. This committee is charged with advising the minister of health on what health services the government should purchase for the New Zealand population.

1 Kawachi I, Wilson $\mathrm{N}$. The evolution of antihypertensive treatment. Soc $S c$ Med 1990;31:1239-43.

2 MacMahon S, Peto R, Cutler J, Collins R, Sorlie P, Neaton J, et al. Blood pressure, stroke and coronary heart disease. Part 1. Prolonged differences in blood pressure: prospective observational studies corrected for regression dilution bias. Lancet 1990;335:765-74.

3 Anderson $\mathrm{KM}$, Wilson PWF, Odell PW, Kannel WB. An updated coronary risk profile. A statement for health professionals. Circulation 1991;83:356-

4 Joint National Committee. The 1988 report of the Joint National Committec on Detection, Evaluation and Treatment of High Blood Pressure. Arch Intern Med 1988:148:1023-38.

5 Guidelines Sub-Committee 1989 Guidelines for the management of mild hypertension: memorandum from a WHO/ISH meeting. $f$ Hypertens hypertension:

6 British Hypertension Working Party. Treating mild hypertension. $B M \nearrow$ 1989;298:694-8

7 Collins R, Peto R, MacMahon S, Herbert P, Fiechbach NH, Eberein KA et al. Blood pressure, stroke, and coronary heart disease. Part 2. Short-term reductions in blood pressure: overview of randomised drug trials. Lancet 1990;335:827-38

8 Russel D, Wilson N. Life in New Zealand survey commission report. Executive overview. Dunedin: University of Otago, 1991.

9 Carlsen JE, Kober L, Torp-Pendersen C, Johansen P. Relationship between dose of bendrofluazide, antihypertensive effect, and adverse biochemical effects. BMY 1990;300:975-8.

10 Cruikshank JM, Thorp JM, Zacharias FJ. Benefits and potential harm of lowering high blood pressure. Lancet 1987; ;:581-4.

11 BBPP Research Group. The Beta-Blocker Pooling Project (BBPP): subgroup findings from randomized trials in post infarct patients. Eur Heart $f$ 1988;9:8-16.

12 Pfeffer MA, Braunwald E, Lemuel AM, Basta L, Brown EJ, Cuddy TE, et al. Effect of captopril on mortality and morbidity in patients with left ventricular dysfunction after myocardial infarction. Results of the surviva and ventricular enlargement study. N Engl f Med 1992;327:669-77.

(Accepted 24 April 1993)

\title{
Health professionals and South Africa: supporting change in the health sector
}

\author{
Tony Waterston, Anthony Zwi
}

Now that political change is on the way in South Africa, what should be the position of doctors who are invited to visit the country? Does the "academic boycott" still have relevance? Waterston and Zwi review the case for and against an academic boycott policy, using evidence collected during the recent visit by Physicians for Human Rights (UK) and the Johannes Wier Foundation. The health system in South Africa is still inequitable, and despite progress towards desegregation in hospitals there is little momentum towards universal provision of primary health care, especially in the rapidly growing townships around big cities. The authors consider that pressure on the government should be maintained by outside organisations but that support directed towards appropriate health care should be encouraged, particularly in public health and primary health care.

\section{Background}

The publication of the report of the Physicians for Human Rights (UK) and Johannes Wier Foundation on apartheid and health care ${ }^{1}$ provides an opportunity to review policy in relation to the boycott of South African health services and related institutions.

The boycott, nominally known as the "academic boycott" but extending beyond academics and their institutions, was introduced at the request of the African National Congress and was supported by its allies, both in South Africa and abroad. The African National Congress considered it necessary to institute a set of measures to isolate South Africa in the economic, military, cultural, sporting, and academic spheres of life. It was argued that this would increase pressure for change from business as well as from sports enthusiasts and academics by making it clear that apartheid was totally unacceptable to the world community and that the penalties for maintaining the status quo would increase. At the same time, trade and military sanctions would weaken the ability of the state to repress opposition within the country and to destabilise the surrounding states. The African National Congress argued that no part of society should be spared by the boycott.

In the health sector, apartheid ensured the inequitable distribution and quality of health care between black and white, urban and rural, wealthy and poor. The training of medical and allied health personnel was deeply divided: medical schools were largely segregated by race, with even the more liberal schools including only a minority of black students and having even fewer blacks on their staff. Furthermore, the establishment medical bodies, such as the Medical Association of South Africa and the South African Medical and Dental Council, played deeply divisive roles by not challenging the impact of apartheid in health and even giving tacit support to doctors who explicitly abused their ethical responsibilities, such as the doctors involved in the case of Stephen Biko. ${ }^{3}$

A policy of isolation was seen as the mechanism whereby overseas doctors could make clear their absolute abhorrence of apartheid. It would also encourage health professionals in South Africa to challenge apartheid and make the state realise that only fundamental change would allow their acceptance into the world community. Any benefits from international medical exchange would be far outweighed by progress towards ending apartheid.

Opponents of the African National Congress's stance took the view that the medical ethic of internationalism, the free exchange of knowledge, and the commitment of care for patients from all backgrounds takes precedence over political campaigning. It was argued that the strategy may be counterproductive and lead to acceptance of the status quo. ${ }^{4}$ Despite this widely canvassed view many medical organisations in the United Kingdom, including the British Medical Association, supported the boycott: the BMA withdrew from the World Medical Association because of its refusal to expel South Africa. Nevertheless, some doctors and medical students continued to travel to South Africa and its bantustans for training and experience. 